\title{
Parameters of the seed output device of the ergot isolation machine
}

\author{
Viktor Saitov ${ }^{1,2, *}$, Vyacheslav Farafonov ${ }^{2}$, and Aleksey Saitov ${ }^{1}$ \\ ${ }^{1}$ Federal Agrarian Scientific Center of the North-East, 166 A, Lenin str., Kirov, 610007, Russia \\ ${ }^{2}$ Vyatka State Agrotechnological University, 133, October ave., Kirov, 610017, Russia
}

\begin{abstract}
Grains of rye, wheat, barley and oats are often infected with poisonous ergot fungi. Therefore, it is necessary to clean the grain from harmful impurities. Modern machines do not provide the isolation of ergot sclerotia from grain due to the closeness of their properties in terms of air flow rate and linear dimensions. Cleaning seeds from ergot sclerotia, which have a density lower than the density of the grain, is possible in an aqueous solution of salt. When developing such a machine, research is required to study the residence time of grain in an aqueous salt solution. Grains are considered in the form of a transverse cylinder and an elongated ellipsoid of rotation with numerical values of the parameters: density $\rho z=1.2 \ldots 1.5 \cdot 103 \mathrm{~kg} / \mathrm{m} 3$, length $\mathrm{l} z=5.0 \ldots 10.0 \cdot 10-3 \mathrm{~m}$, width $\mathrm{b}=$ $1.4 \ldots 3.6 \cdot 10-3 \mathrm{~m}$ and thickness $\delta=1.2 \ldots 3.5 \cdot 10-3 \mathrm{~m}$. Theoretical studies were carried out on the basis of methods of mathematical modeling, classical mechanics using the laws of hydrodynamics. It was found that when using in the machine for the isolation of toxic ergot sclerotia from the grain of an aqueous solution of salt with a density $\rho \mathrm{zh}=1000 \ldots 1150$ $\mathrm{kg} / \mathrm{m} 3$ and a height $\mathrm{h} 1=0.35 \ldots 0.60 \mathrm{~m}$ in a bath, the total time total of seeds residence varies within 7.6...18.8 s. During this time, the seeds are moistened superficially, to eliminate which it is enough to blow them under the pressure of atmospheric air.
\end{abstract}

\section{Introduction}

The grain of the main grain crops (rye, wheat, barley and oats) is the oldest human food and feed for farm animals. However, cereals such as winter rye, wheat, barley and oats are often infected with poisonous ergot fungi [1,2].

Currently, grain production is mechanized. Harvesting is carried out by combine harvesters $[3,4,5]$. After threshing the grain mass with these combines, due to the imperfection of their cleaning mechanism, the grain heap contains grain, organic and mineral impurities, as well as harmful impurities, which include poisonous ergot sclerotia $[6,7,8]$.

Therefore, to obtain grain suitable for food, technical and seed purposes, the separation of various impurities from the grain heap is carried out by machines of preliminary, primary and secondary cleaning [9-12].

\footnotetext{
* Corresponding author: vicsait-valita@e-kirov.ru
} 
These machines are complex and therefore costly. These machines do not provide the release of poisonous ergot sclerotia in one technological process due to the closeness of their physical and mechanical properties in terms of air flow velocity and linear dimensions (width, thickness and length) [13-23].

Research on improving the design and technological process of these machines does not solve the problem noted $[24,25]$.

However, the grains of the main grain crops have a higher specific gravity ( $\rho z=$ $1.2 \ldots 1.5 \cdot 103 \mathrm{~kg} / \mathrm{m} 3)$ than ergot sclerotia $(\rho c=0.9 \ldots 1.15 \cdot 103 \mathrm{~kg} / \mathrm{m} 3)$. Therefore, almost $100 \%$ removal of ergot sclerotia from seeds, which differ in density from grain, is possible in aqueous solutions of various inorganic salts [26].

This circumstance requires the creation of a less energy-intensive and more efficient machine for the isolation of toxic ergot sclerotia from seed material. This machine should have simple, easy-to-adjust and maintain main working parts [27].

One of the ways to solve this issue is to create a machine for the isolation of toxic ergot from grain, consisting of a bath with an aqueous solution of salt, conveyors of seeds and waste, a hopper with a feeder and a tank with an aqueous solution of salt [28].

When developing such a machine, research is required to study the residence time of grain in an aqueous salt solution. If the grain is aqueous salt solution for a long time, it is possible for liquid to penetrate through their shell. This circumstance causes an increase in grain moisture. Increasing grain moisture requires additional drying costs for long-term storage of seeds. This circumstance also worsens the flowability of seeds when sowing with seeders. In addition, the penetration into the seed of an aqueous solution of chlorinecontaining salt can have a negative effect on its germination. Therefore, it becomes necessary to consider the process of withdrawing seeds from a bath with an aqueous solution of salt of the machine for the isolation of toxic ergot sclerotia.

\section{Materials and methods}

Theoretically, the residence time of grains in an aqueous solution of salt of a machine for the isolation of toxic ergot sclerotia from grain is considered. Grains are considered as a model of a transverse cylinder and an elongated ellipsoid of revolution. In accordance with this, the scientific concept of a cylindrical grain was introduced for the model of a transverse cylinder, and a spheroidal grain for the model of an ellipsoid of revolution.

For theoretical calculations, the following numerical values of the grain parameters were taken: density $\rho z=1.2 \ldots 1.5 \cdot 103 \mathrm{~kg} / \mathrm{m} 3$, length $\mathrm{lz}=5.0 \ldots 10.0 \cdot 10-3 \mathrm{~m}$, width $\mathrm{b}=$ $1.4 \ldots 3.6 \cdot 10-3 \mathrm{~m}$ and thickness $\delta=1.2 \ldots 3.5 \cdot 10-3 \mathrm{~m}$. These parameters correspond to the numerical values of the parameters of grains of the main grain crops (rye, wheat, barley, and oats) [26].

Theoretical studies on the immersion of grains in a liquid of various density pzh and their removal from a bath with an aqueous salt solution were carried out on the basis of mathematical modeling methods and classical mechanics.

The experimental data were processed on a SAMSUNG NP-R540H personal computer using the Excel 2013 statistical data processing application from the Microsoft Office 2013 office software package, as well as using the SigmaPlot 11.0 special statistical data processing software. The resulting graphic dependencies were created in the vector graphics editor CorelDRAW 12. 


\section{Results and discussion}

When a grain, considered in the form of models of a transverse cylinder (cylindrical grain) and an elongated ellipsoid of revolution (spheroidal grain) [29], falls from a minimum height $h$ onto the surface of the liquid to overcome surface tension forces, it moves in it at a speed $\mathrm{vz}$ to the bottom of the tank 1 of the machines for the isolation of toxic ergot sclerotia. Further, the grains move at a speed vup along the bottom of the bath by scrapers 5 of the lower branch of the conveyor 2 and are taken out through the sloping board 3 . When the conveyor 2 moves rye seeds in the unloading direction, the aqueous salt solution from them flows down the sloped bottom back into the bath 1 through the gap $\Delta$ between the working the edge of the scrapers 5 and the bottom.

The general scheme of immersing and removing of rye seeds from the bath of the machine for the isolation of toxic ergot sclerotia with an aqueous solution of salt is shown in Figure 1.

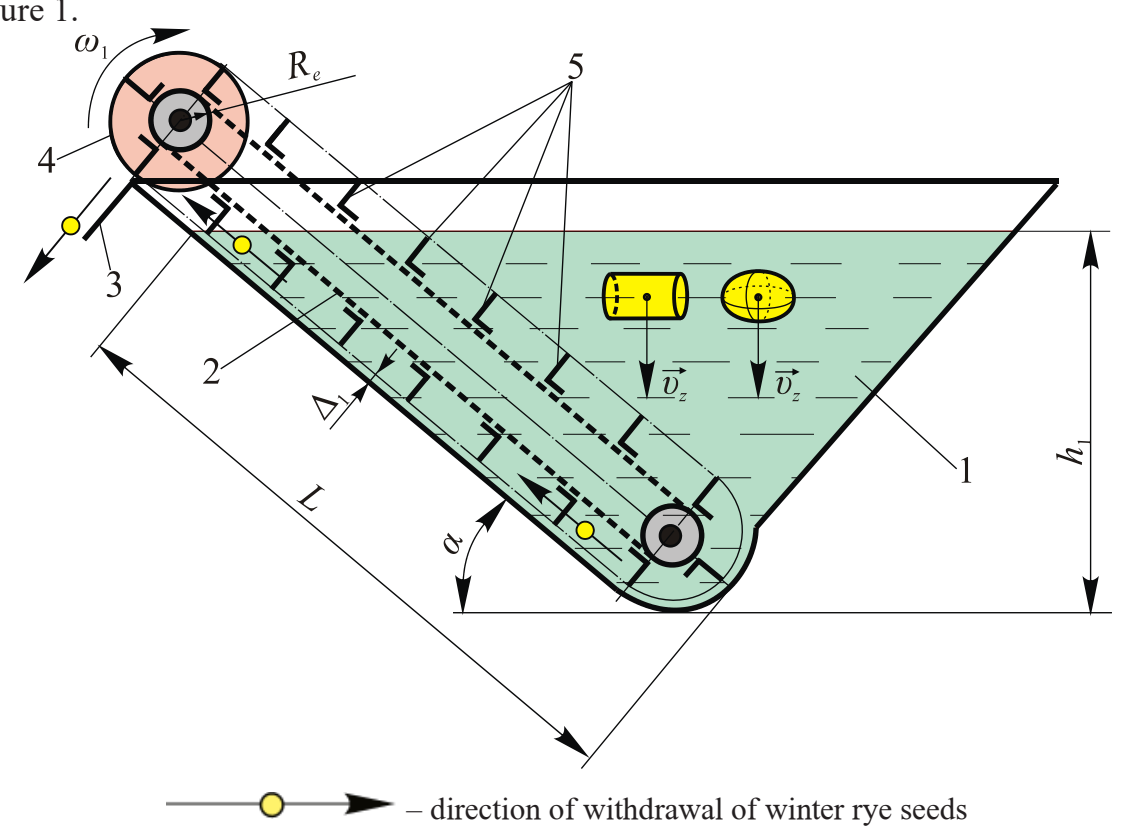

Fig. 1. General scheme of immersion and removal of rye seeds from the bath of the machine for the isolation of toxic ergot sclerotia with an aqueous solution of salt: 1 - bath; 2 - conveyor; 3 - pitched board; 4 - leading sprocket; 5 - scrapers.

From the moment the grain is immersed in the liquid, the time tп of its movement in it to the bottom of the bath is:

$$
t_{n}=\frac{\mathbb{H}_{1}}{v_{\mathrm{z}}}
$$

where $\mathrm{h} 1$ - the height of the aqueous solution of salt in the bath of the machine for the isolation of toxic ergot sclerotia, $\mathrm{m}$.

The time tup of the lifting of grains from an aqueous solution of salt by the conveyor scrapers of the machine for the isolation of toxic ergot sclerotia is

$$
t_{u p}=\frac{L}{v_{u p p}}
$$


where $\mathrm{L}$ - the length of the bottom of the bath with an aqueous solution of salt of the machine for the isolation of toxic ergot sclerotia under the conveyor for removing rye seeds, m;

vup - linear speed of rye seeds lifting along the bottom of the bath by the conveyor of the machine for the isolation of toxic ergot sclerotia, $\mathrm{m} / \mathrm{s}$.

The length of the bottom of the bath with an aqueous solution of salt under the conveyor for removing rye seeds is determined by the formula:

$$
L=\frac{\|_{1}}{\sin \alpha},
$$

where $\alpha$ - the angle of inclination of the bottom of the bath of the machine for the isolation of toxic ergot sclerotia to the horizontal, deg.

Taking into account the need to maintain the continuity of the technological process for removing rye seeds from the bath of the machine for the isolation of toxic sclerotia and excluding their accumulation in it, the time tn of immersing the seeds to the bottom of the bath should be no less than the time tup of lifting them from an aqueous solution of salt with the conveyor scrapers of the machine for the isolation of ergot sclerotia. It is also necessary that the geometric dimensions of the scrapers (width and height), their number and distance between them correspond to the requirement: the flow of grains falling in the solution was not more than the flow of grains taken out by the conveyor.

For the case when $t \Pi=$ tup the following relation is fulfilled:

$$
\frac{B_{1}}{L}=\frac{D_{z}}{v_{u p}}=\sin \alpha,
$$

from where

$$
v_{\mathrm{up}}=\frac{v_{z}}{\sin \alpha} .
$$

Then the total residence time of rye seeds in the bath of the machine for the isolation of toxic ergot sclerotia with an aqueous solution of salt, taking into account expressions (1) and (2), will be

$$
t_{\text {total }}=\frac{2 H_{1}}{D_{z}}
$$

The accumulation of grains when removing grain depends on the gap $\Delta$ between the bottom edge of the scrapers and the bottom of the bath.

The surface of the dependence of the total residence time ttotal of rye seeds in an aqueous solution of salt of the machine for the isolation of toxic ergot sclerotia on the density $\rho$ zh of the solution and its height h1 is shown in Figure 2, taking into account the expressions for the velocity oz of movement of a weevil in a liquid, considered in the form of models of a transverse cylinder (cylindrical grain) and an elongated ellipsoid of revolution (spheroidal grain) and presented in work [30].

The surface of the dependence ttotal $=\mathrm{f}(\rho \mathrm{zh}, \mathrm{h} 1)$ is constructed for the calculated average velocities $\mathrm{vz}$ mean of grain movement in a liquid with a density of $\rho \mathrm{zh}=$ $1000 \ldots 1150 \mathrm{~kg} / \mathrm{m} 3(\mathrm{vz}$ mean $1000=0.092 \mathrm{~m} / \mathrm{s}$, vz mean $1030=0.087 \mathrm{~m} / \mathrm{s}$, vz mean $1060=$ $0.082 \mathrm{~m} / \mathrm{s}$, vz mean $1090=0.076 \mathrm{~m} / \mathrm{s}$, vz mean $1120=0.070 \mathrm{~m} / \mathrm{s}$, vz mean $1150==0.064$ $\mathrm{m} / \mathrm{s})$. The height $\mathrm{h} 1$ of an aqueous solution of salt varies for machines for the isolation of toxic ergot sclerotia in terms of density in liquid from rye grains within the range of $0.35 \ldots 0.60 \mathrm{~m}$, differing in size in terms of productivity. 


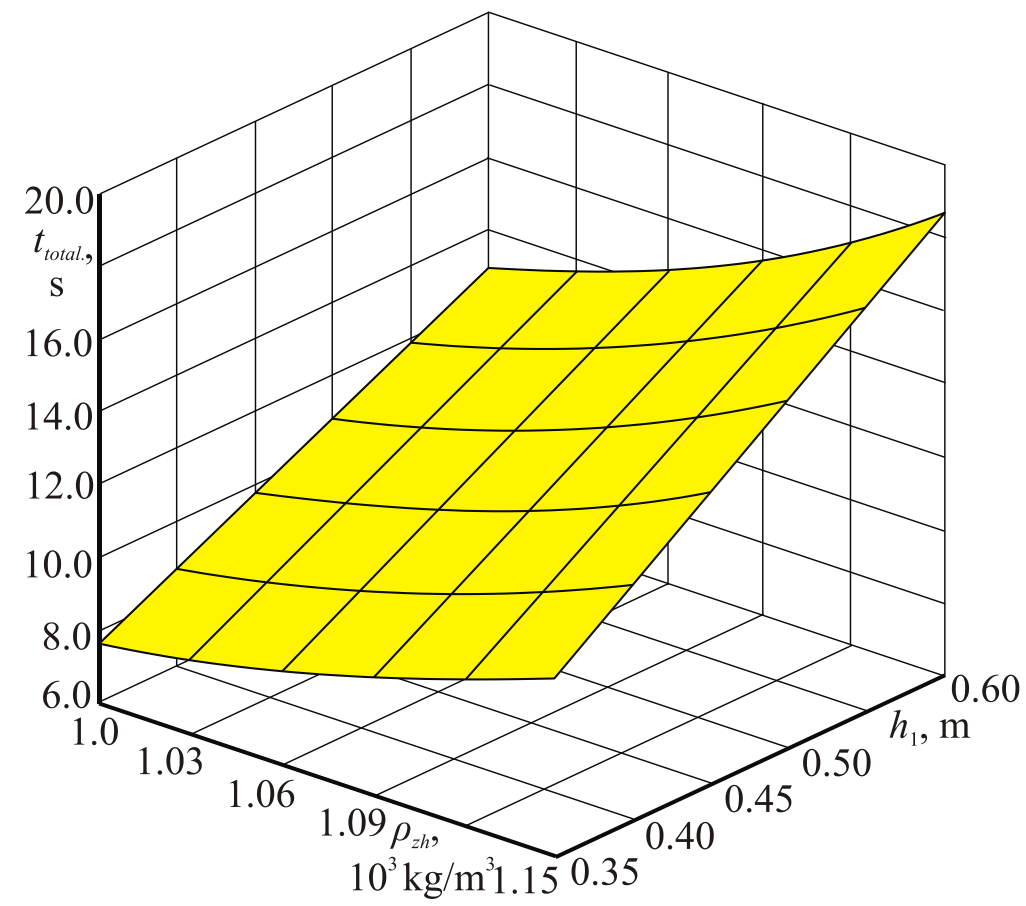

Fig. 2. The surface of the dependence of the total residence time ttotal of rye seeds in an aqueous solution of salt of the machine for the isolation of toxic ergot sclerotia on the density $\rho$ zh of the solution and its height h1.

From the analysis of the surface it can be seen that with an increase in the density $\rho z h$ of the aqueous salt solution and its height $\mathrm{h} 1$ in the bath, the time ttotal of the grain in it increases. With the density of the liquid $\rho z \mathrm{~h}=1000 \mathrm{~kg} / \mathrm{m} 3$ (water) and its height $\mathrm{h} 1=0.35$ $\mathrm{m}$, the total time ttotal of the stay of rye seeds in it is $7.6 \mathrm{~s}$, and at a height of $\mathrm{h} 1=0.60 \mathrm{~m}$ this time is ttotal $=13.0 \mathrm{~s}$. At a density of an aqueous solution of salt $\rho z h=1150 \mathrm{~kg} / \mathrm{m} 3$, corresponding to the upper limit of the density $\rho c$ of ergot sclerotia, and its height $\mathrm{h} 1=0.35$ $\mathrm{m}$, the time ttotal $=10.9 \mathrm{~s}$, and in the case of a maximum height $\mathrm{h} 1=0.60 \mathrm{~m}$ of an aqueous solution salt in the bath of the machine for the isolation of ergot sclerotia, the time ttotal, the residence time of the grain in it increases to $18.8 \mathrm{~s}$.

Consequently, the total time ttotal the stay of rye seeds in an aqueous solution of salt of the machine for the isolation of toxic ergot sclerotia is completely insignificant. In such a short time, an aqueous salt solution is not able to pass through the grains shell inside. This excludes an excessive increase in grain moisture. To eliminate surface moisture of the grain, it is enough to blow it under the pressure of external or heated atmospheric air.

The linear speed vup of rye seed lifting along the bottom of the bath by the conveyor of the machine for the isolation of toxic ergot sclerotia is determined by the formula [31]:

$$
v_{\mathrm{up}}=\omega_{1} R_{e}=\frac{2 \pi n_{1} R_{e}}{60}=\frac{\pi m_{1} R_{e}}{30},
$$

where $\omega 1$ - angular speed of rotation of the drive shaft of the conveyor of rye seeds of the machine for the isolation of toxic ergot sclerotia, rad./s;

$\mathrm{Re}$ - the outer radius of the circle of the leading sprocket on the drive shaft of the rye seed conveyor of the machine for the isolation of toxic ergot sclerotia, m;

$\Pi 1$ - frequency of rotation of the drive shaft of the rye seed conveyor of the machine for the isolation of toxic ergot sclerotia, min-1. 
Then from expression (7), taking into account formula (5), the frequency n1 of rotation of the drive shaft of the rye seed conveyor of the machine for the isolation of toxic ergot sclerotia is determined

$$
n_{1}=\frac{30 v_{z}}{\pi R_{2} \sin \alpha}
$$

The diameter of the outer circumference of the leading sprocket on the drive shaft of the rye seed conveyor machine for the isolation of toxic ergot sclerotia is expressed [32]

$$
D_{e}=\frac{t_{1}}{\operatorname{tg} \frac{1+0^{\mathbb{1 0}}}{z}}
$$

where $\mathrm{t} 1$ - leading sprocket pitch on the drive shaft of the rye seed conveyor, $\mathrm{mm}$;

$\mathrm{z}$ - number of the leading sprocket teeth on the drive shaft of the rye seed conveyor, pc.

Then, taking into account expression (9), introducing a coefficient of 2.0 due to the volumetric intake of grain by scrapers from the bottom of the bath, the rotational speed of the drive shaft of the rye seed conveyor, represented by formula (8), is determined as follows (min-1):

$$
n_{1}=\frac{3 \cdot 0 \cdot 10^{4} v_{z} \operatorname{tg} \frac{110^{a}}{x}}{\pi t_{1} \sin \alpha} .
$$

The obtained expression (10) makes it possible to determine the frequency $\Pi 1$ of rotation of the drive shaft of the rye seed conveyor of the machine for the isolation of poisonous ergot sclerotia, depending on the pitch $\mathrm{t} 1$ of the leading sprocket and the number $\mathrm{z}$ of its teeth, as is customary in technical calculations.

The surface of the dependence of the frequency п1 of rotation of the drive shaft of the conveyor for removing rye seeds from an aqueous solution of salt on its density $\rho$ zh and the number $\mathrm{z}$ of the teeth of the leading sprocket is shown in Figure 3, taking into account the expressions for the velocity $\mathrm{vz}$ of grain movement in a liquid, considered in the form of models of a transverse cylinder (cylindrical grain) and an elongated ellipsoid of revolution (spheroidal grain) and presented in work [30].

To determine the frequency $\mathrm{n} 1$ of rotation of the drive shaft of the conveyor for removing rye seeds from the bath, the step of the leading sprocket $\mathrm{t} 1=12.7 \mathrm{~mm}$ and the angle of inclination of the bath bottom $\alpha=40^{\circ}$ were adopted as the most rational parameters for this design of the machine for the isolation of toxic ergot sclerotia from rye grain.

The surface of the dependence $\Pi 1=\mathrm{f}(\rho \mathrm{zh}, \mathrm{z})$ is constructed for the calculated average velocities vz mean of grain movement in a liquid with a density of $\rho z h=1000 \ldots 1150$ $\mathrm{kg} / \mathrm{m} 3(\mathrm{vz}$ mean $1000=0.092 \mathrm{~m} / \mathrm{s}$, vz mean $1030=0.087 \mathrm{~m} / \mathrm{s}$, vz mean $1060=0.082 \mathrm{~m} / \mathrm{s}, \mathrm{vz}$ mean $1090=0.076 \mathrm{~m} / \mathrm{s}$, vz mean $1120=0.070 \mathrm{~m} / \mathrm{s}$, vz mean1 $150==0.064 \mathrm{~m} / \mathrm{s}$ ).

From the obtained graph it follows that with an increase in the density $\rho z h$ of an aqueous solution of salt and an increase in the number $\mathrm{z}$ of the teeth of the leading sprocket on the drive shaft of the conveyor, the frequency $\Pi 1$ of its rotation decreases. When varying the number $\mathrm{z}$ of the teeth of the leading sprocket on the drive shaft of the conveyor within $24 . .34 \mathrm{pc}$. the maximum values of its rotation frequency $\Pi 1$ are observed at a liquid density $\rho z h=1000 \mathrm{~kg} / \mathrm{m} 3$. This is due to the faster immersion of the grain in water than in a salt solution, and, accordingly, the need to remove the grain from the bath with a conveyor with a high frequency $\Pi 1$ of its rotation. So, in the case of using a leading sprocket with an increasing number of teeth $\mathrm{z}=24,26,28,30,32$ or 34 pc., the frequency $\Pi 1$ of rotation of the conveyor shaft decreases and, accordingly, is $14.2 ; 13.1 ; 12.1 ; 11.3 ; 10.6$ or 10.0 min-1. 


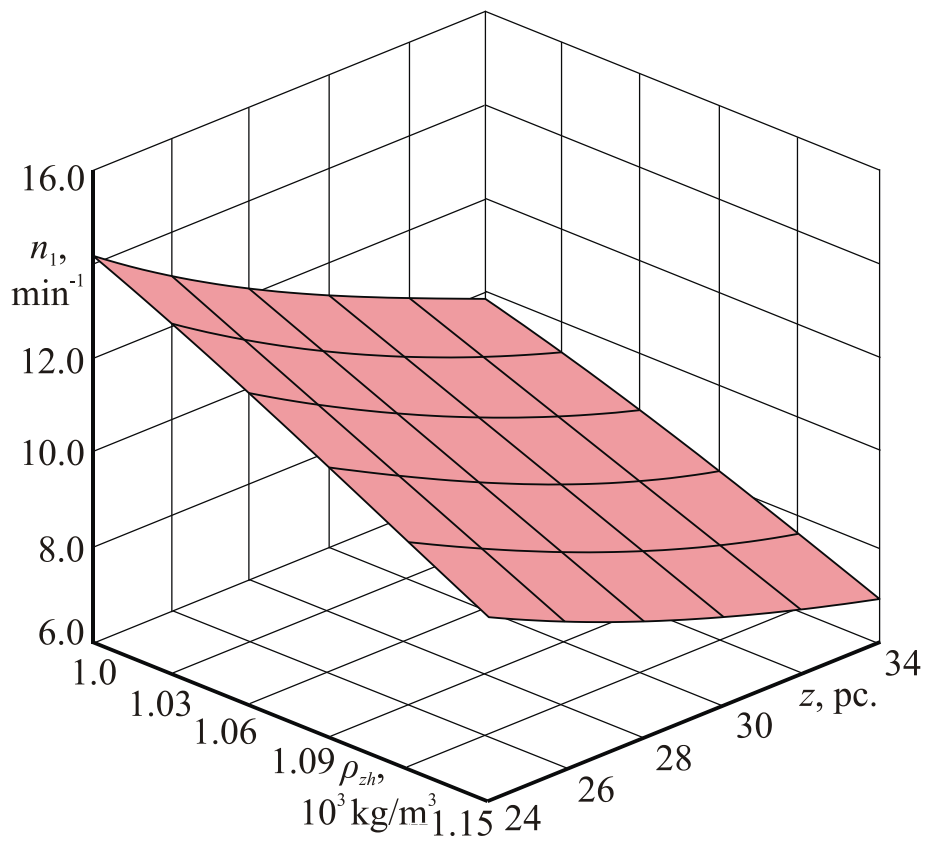

Fig. 3. The surface of the dependence of the frequency $\Pi 1$ of rotation of the drive shaft of the conveyor for removing rye seeds from an aqueous solution of salt of the machine for the isolation of toxic ergot sclerotia on the density pzh of the solution and the number $\mathrm{z}$ of the teeth of the leading sprocket.

The minimum values of the frequency $\Pi 1$ of rotation of the conveyor are fixed at the density of an aqueous solution of salt $\rho \mathrm{zh}=1150 \mathrm{~kg} / \mathrm{m} 3$, corresponding to the upper limit of the density $\rho c$ of ergot sclerotia. In the case of using a leading sprocket with a number of teeth $z=24$ pc. the frequency $\Pi 1$ of rotation of the conveyor is $9.9 \mathrm{~min}-1$, and with an increase in the parameters $\mathrm{z}$ of the leading sprocket, the values of $\Pi 1$ decrease and at $\mathrm{z}=34$ pc. are already make up 6.9 min-1.

Thus, in order to carry out the technological process with proper efficiency by a machine for the isolation of toxic ergot sclerotia, the frequency $\Pi 1$ of rotation of the conveyor for removing rye seeds from an aqueous salt solution depends on its density $\rho z h$ and the number $\mathrm{z}$ of the teeth of the leading sprocket.

\section{Conclusion}

When using an aqueous solution of salt with a density $\rho z \mathrm{~h}=1000 \ldots 1150 \mathrm{~kg} / \mathrm{m} 3$ and a height $\mathrm{h} 1=0.35 \ldots 0.60 \mathrm{~m}$ in the bath in the machine for the extraction of ergot sclerotia from rye grain, the total residence time ttotal of rye seeds varies within $7.6 \ldots 18.8 \mathrm{~s}$. In such a short time, rye seeds are moistened only superficially, to eliminate which it is enough to blow them under the pressure of outside or heated atmospheric air.

In this case, the frequency $\Pi 1$ of rotation of the rye seed conveyor is $6.9 \ldots 14.2 \mathrm{~min}-1$ using of the leading sprocket with the number of teeth $z=34,32,30,28,26$ and 24 pc. respectively. Due to the possibility of using the developed machine also for dressing seeds in an aqueous emulsion of chemicals, the density of which will be close to the density of water, for the proper efficiency of the technological process, the rotation frequency $\mathrm{n} 1$ of the rye seed conveyor should be at least 14.2 min-1 using of the leading sprocket with a quantity number of teeth $\mathrm{z}=24 \mathrm{pc}$. 
The work was performed in the framework of the State task of the Federal Agrarian Scientific Center of the North-East (No 0767-2019-0094) «Creation of innovative technologies and technologies of a new generation for mechanization of crop and livestock production adapted to the climatic conditions of the North-East of the European part of Russia» and on the scientific topic «Physical and mathematical modeling of grain materials separation» of the Department of mathematics and physics of the Vyatka State Agrotechnological University (Kirov, Russia).

\section{References}

1. L.M. Schekleina, T.K. Sheshegova The problem of ergot grains (Claviceps purpurea (Fr.) Tul.): past and present (review), Theoretical and Applied Ecology 1, 5-12 (2013) DOI: http://doi.org/10.25750/1995-4301-2013-1-005-012 (In Russ.)

2. T.K. Sheshegova, L.M. Schekleina, E.I. Utkina, Immunological characteristics of varieties of winter rye, Agricultural science of the Euro-North-East 65(4), 30-35 (2018) DOI: https://doi.org/10.30766 / 2072-9081.2018.65.4.30-351 (In Russ.)

3. V.I. Orobinsky, A.M. Gievsky, I.V. Baskakov, A.V. Chernyshov, Seed refinement in the harvesting and post-harvesting process, Adv. in Eng. Res. 870-874 (2018)

4. N. Aldoshin, O. Didmanidze, Harvesting Lupinus albus axial rotary combine harvesters, Res. in Agricul. Eng. 64(4), 209-214 (2018) DOI: http://doi.org/10.17221/107/2017-RAE

5. N. Aldoshin, O. Didmanidze, N. Lylin, M. Mosyakov, Work improvement of air-andscreen cleaner of combine harvester, Engineering for Rural Development: Proceedings of 18th International Scientific Conference 18, 100-104 (2019) DOI: http://doi.org/10.22616/ERDev2019.18.N110

6. L.M. Schekleina, T.K. Sheshegova, Ergot harmful in new varieties of winter rye in the Kirov region, Bulletin of Mari State University 2(14), 83-90 (2018) DOI: https://doi.org/10.30914 / 2411-9687-2018-4-2-83-89 (In Russ.)

7. L.M. Schekleina, The influence of weather factors on certain periods of development of the fungus Slavicep spurpurea (Fr.) Tul and the level of ergot erosion in the Kirov region, Agricultural science of the Euro-North-East 20(2), 134-143 (2019) DOI: https://doi.org/10.30766/2072-9081.2019.20.2. 134-143 (In Russ.)

8. T.K. Sheshegova, L.M. Schekleina, V.P. Zhelifonova, T.V. Antipova, B.P. Baskunov, A.G. Kozlovsky, The resistance of rye varieties to ergot and the content of ergot alkaloids in sclerotia claviceps purpurea in the conditions of the Kirov region, Mycology and phytopathology 53(3), 177-182 (2019) DOI: https://doi.org/10.1134 / S0026364819030127 (In Russ.)

9. M.S. Volkhonov, I.B. Zimin, Yu.N. Ostrovsky, Analysis of the state of preliminary cleaning of grain in farms of the north-western region of the Russian Federation and prospects for improvement, Bulletin of the Kazan State Agrarian University 15, 2(58), 82-86 (2020) DOI: https://doi.org/10.12737/2073-0462-2020-82-86 (In Russ.)

10. A.I. Burkov, A.L. Glushkov, V.A. Lazykin, Comparative studies of the effectiveness of the functioning of the pneumatic separation channels of the fractional pneumatic separator of seeds, Bulletin of the Voronezh State Agrarian University 12, 3 (62), 2631 (2019) DOI: https://doi.org/10.17238/issn2071-2243.2019.3.26 (In Russ.)

11. M.K. Kharitonov, A.M. Gievsky, V.I. Orobinsky, A.V. Chernyshov, I.V. Baskakov, Improving the efficiency of sieve cleaning of grain cleaning machines, Bulletin of the Voronezh State Agrarian University 13, 1(64), 19-27 (2020) DOI: https://doi.org/10.17238/issn2071-2243.2020.1.19 (In Russ.) 
12. V.D. Galkin, A.D. Galkin, V.A. Khandrikov, A.F. Fedoseev, M.S. Nakaryakov, Parameters and modes of cleaning seeds on a vibro-pneumatic separator of improved design, Perm Agrarian Bulletin 1 (29), 4-12 (2020) DOI: https://doi.org/10.24411/2307-2873-2020-10012 (In Russ.)

13. V.I. Orobinsky, A.P. Tarasenko, A.M. Gievsky, A.V. Chernyshov, I.V. Baskakov, Improving the mechanization of high-quality seed production, Advances in Engineering Research 849-852 (2018) DOI: https://doi.org/10.2991/agrosmart18.2018.159

14. I. Badretdinov, S. Mudarisov, M. Tuktarov, E. Dick, S. Arslanbekova, Mathematical modeling of the grain material separation in the pneumatic system of the graincleaning machine, Journal of Applied Engineering Science 4(17), 529-534 (2019) DOI: https://doi.org/10.5937/jaes17-22640

15. A.M. Gievsky, V.A. Gulevsky, V.I. Orobinsky, Ways to increase the performance of universal grain cleaning machines, Bulletin of the Federal State Educational Establishment of Higher Professional Education "Moscow State Agroengineering University named after VP Goryachkin" 3(85), 12-16 (2018) DOI: https://doi.org/10.26897 / 1728-7936-2018-3-12-16 (In Russ.)

16. P. Savinyh, Y. Sychugov, V. Kazakov, S. Ivanovs, Development and theoretical studies of grain cleaning machine for fractional technology of flattening forage grain. In: Engineering for Rural Development: 17th International Scientific Conference Engineering for Rural Development, Proceedings 124-130 (2018) DOI: https://doi.org/10.22616/ERDev2018.17.N156

17. A.M. Gievsky, V.I. Orobinsky, A.P. Tarasenko, A.V. Chernyshov, D.O. Kurilov, Substantiation of basic scheme of grain cleaning machine for preparation of agricultural crops seeds, IOP Conference Series: Materials Science and Engineering 327, 042035 (2018) DOI: https://doi.org/10.1088/1757-899X/327/4/042035

18. V.E. Saitov, R.F. Kurbanov, A.N. Suvorov, Assessing the adequacy of mathematical models of light impurity fractionation in sedimentary chambers of grain cleaning machines, Procedia Engineering 150, 107-110 (2016) DOI: https://doi.org/10.1016/j.proeng.2016.06.728

19. V.E. Saitov, V.G. Farafonov, R.G. Gataullin, A.V. Saitov, Research of a diametrical fan with suction channel, IOP Conference Series: Materials Science and Engineering 473 (012009), 1-6 (2018) DOI: https://doi.org/10/1088/1757-899X/457/1/012009

20. V.L. Andreev, Calculation of the effective separation of light impurities in the inertial jalousie-countercurrent dust collector, IOP Conference Series: Materials Science and Engineering International Workshop «Advanced Technologies in Material Science, Mechanical and Automation Engineering» 32097 (2019) DOI: https://doi.org/10.1088/1757-899X/537/3/032097

21. V.I. Orobinsky, A.M. Gievsky, A.P. Tarasenko, A.V. Chernyshov, Study of strength and sowing qualities of seeds of winter wheat with fractional technology of postharvest grain processing, Bulletin of the Voronezh State Agrarian University 12, 62(3), 13-18 (2019) DOI: https://doi.org/10.17238/issn2071-2243.2019.3.13 (In Russ.)

22. Yu.I. Ermoliev, A.A. Doroshenko, S.V. Belov, Simulation of the process of separation of chopped straw in a pneumatic separator with three pneumatic channels, Bulletin of the Don State Technical University 16, 85(2), 59-68 (2016) DOI: https://doi.org/10.12737 / 19691 (In Russ.)

23. V.I. Orobinsky, A.M. Gievsky, A.P. Tarasenko, A.V. Chernyshov, I.V. Baskakov, A study of the effectiveness of cleaning heaps of spring wheat for seed purposes with an 
air-sieve separator, Bulletin of the Voronezh State Agrarian University 12, 61(2), 3442 (2019) DOI: https://doi.org/10.17238/issn2071-2243.2019.2.34 (In Russ.)

24. A.I. Burkov, A.L. Glushkov, V.A. Lazykin, Calculation of particle trajectories in a pneumatic separation channel by various methods, Agrarian science of Euro-NorthEast 21, 1, 62-70 (2020) DOI: https://doi.org/10.30766/2072-9081.2020.21.1.62-70 (In Russ.)

25. M.K. Kharitonov, A.M. Gievsky, V.I. Orobinsky, A.V. Chernyshov, I.V. Baskakov, Studying the design and operational parameters of the sieve module of the grain cleaning machine, IOP Conference Series: Earth and Environmental Science 012021 (2020) DOI: https://doi.org/10.1088 / 1755-1315 / 488/1/012021

26. V.E. Saitov, V.G. Farafonov, A.V. Saitov, Experimental substantiation of the effective height of a grain falling by a stream of liquid in an ergot release device, IOP Conference Series: Earth and Environmental Science 341 (012123), 1-6 (2019) DOI: https://doi.org/10.1088/1755-1315/341/1/012123

27. K.D. Astanakulov, Y.Z. Karimov, G. Fozilov, Design of a grain cleaning machine for small farms, AMA, Agricultural Mechanization in Asia, Africa and Latin America 42(4), 37-40 (2011)

28. A. Saitov, R. Gataullin, V. Saitov, A machine for separating ergot from rye seeds, Patent RF no. 2689470 (2019)

29. V.A. Sysuev, V.E. Saitov, V.G. Farafonov, A.N. Suvorov, A.V. Saitov, Theoretical background of calculating of the parameters of the device for grain cleaning from ergot sclerotia, Russian Agricultural Sciences 43(3), 273-276 (2017) DOI: https://doi.org/10.3103/S1068367417030156

30. V.E. Saitov, V.G. Farafonov, A.V. Saitov, Analysis of the process of immersion of grains in liquids with different specific gravity, Agricultural Science of the Euro-NorthEast 20(4), 407-419 (2019) DOI: https://doi.org/10.30766/2072-9081.2019.20.4.407419 (In Russ.)

31. I.N. Bronshtein, K.A. Semendyaev, A guide to mathematics for engineers and students of technical colleges (Moscow, Nauka Publ., 1980)

32. V.I. Anurev, Handbook of the designer-machine builder (Moscow, Mechanical Engineering Publ., 2, 2001) 